\title{
Correction to: A New Pathway to 2-Arylbenzoxazoles and 2-Arylbenzothiazoles Via One-Pot Oxidative Cyclization Reactions Under Iron-Organic Framework Catalysis
}

\author{
Son H. Doan ${ }^{1}$. Chau B. Tran ${ }^{1}$ - An. L. N. Cao ${ }^{1}$ Nhan T. H. Le ${ }^{1} \cdot$ Nam T. S. Phan ${ }^{1}$ \\ Published online: 7 June 2021 \\ ๑) Springer Science+Business Media, LLC, part of Springer Nature 2021
}

\section{Correction to: Catalysis Letters (2019) 149:2053-2063 https://doi.org/10.1007/s10562-019-02747-1}

The authors regret that some characterization images of the catalyst were shown incorrectly in the main text and in the Supplementary Data. Figures 13 and 14 in the main text of the paper were rechecked by conducting necessary experiments. Thus, we would like to update Figs. 13 and 14 in the paper, as shown below.

In the Supplementary Data, Figures S1-S7 have been updated. The updated Supplementary Data file has been published online with this Correction.

The authors would like to apologise for any inconvenience caused.

The original article can be found online at https://doi.org/10.1007/ s10562-019-02747-1.

Nhan T. H. Le

lthnhan@hcmut.edu.vn

$\triangle$ Nam T. S. Phan

ptsnam@hcmut.edu.vn

1 Faculty of Chemical Engineering, HCMC University of Technology, VNU-HCM, 268 Ly Thuong Kiet, District 10, Ho Chi Minh City, Viet Nam 


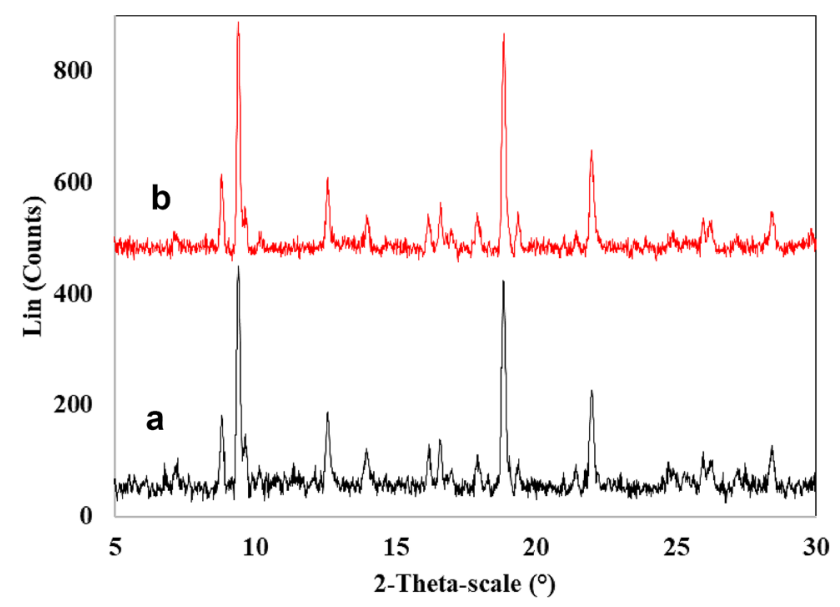

Fig. 13 XRD results of the new (a) and reutilized (b) catalyst

Supplementary Information The online version contains supplementary material available at https://doi.org/10.1007/s10562-021-03683-9.

Publisher's Note Springer Nature remains neutral with regard to jurisdictional claims in published maps and institutional affiliations.

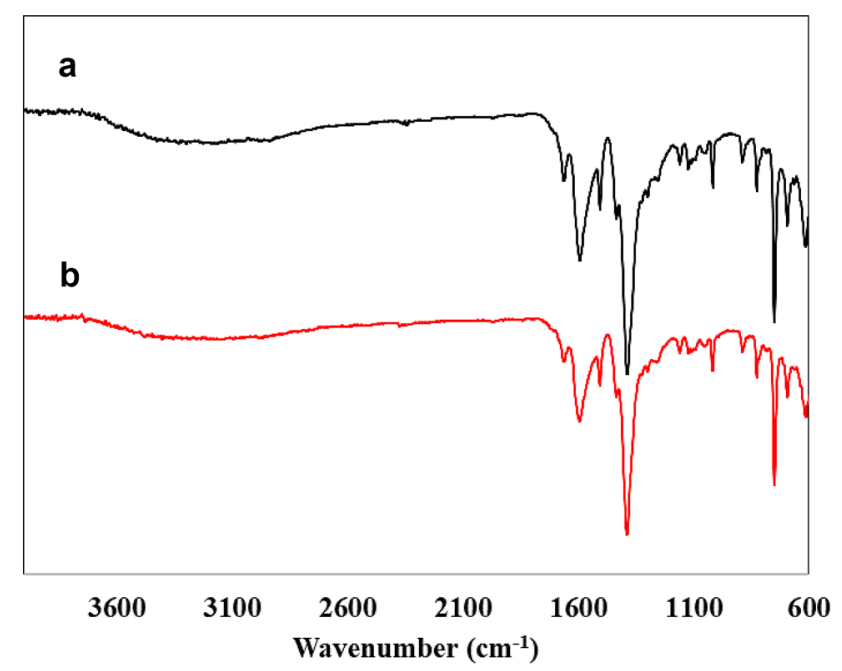

Fig. 14 FT-IR results of the new (a) and reutilized (b) catalyst 